\title{
O DESENVOLVIMENTO RACIONAL DA SUBJETIVIDADE FINITA NA RAZÃO ATIVA DA FENOMENOLOGIA DO ESPÍRITO DE G.W.F. HEGEL'
}

The rational development of finite subjectivity in the active reason of the phenomenology of spirit from G.W.F Hegel

El desarrollo racional de la sujectividad finita en la razon activa de la fenomenogia del espiritu de G.W.F. Hegel

Rafael Ramos Cioquetta ${ }^{2}$ Pontifícia Universidade Católica do Rio Grande do Sul, Porto Alegre, RS, Brasil.

\section{Resumo}

Esta pesquisa buscou tratar a questão que envolve a importância e a função da subjetividade finita na filosofia Hegeliana. Para isso, nos atemos à interpretação de partes da obra que expõe o desenvolvimento da subjetividade como seu tema central, a Fenomenologia do Espírito, de 1807. Nossa interpretação das últimas figuras da Razão nos levou à conclusão de que a subjetividade finita, enquanto individualidade singular participa de maneira fundamental da produção e da efetivação dos conceitos, pois verificamos que devido a sua natureza, determinada como o caráter negativo do espírito, ela nunca é totalmente superada e dissolvida na universalidade.

Palavras chave: Subjetividade. Conceito. Necessidade. Efetividade.

\footnotetext{
O presente trabalho foi realizado com apoio da Coordenação de Aperfeiçoamento de Pessoal Nivel Superior - Brasil (CAPES)

2 Doutor em Filosofia pela Pontifícia Universidade Católica do Rio Grande do Sul (PUCRS), Porto Alegre, Rio Grande do Sul, Brasil. ORCID: http://orcid.org/oooo-0003-4798-3967. E-mail: rafaelcioquetta@gmail.com
} 


\begin{abstract}
This research sought to address the issue that involves the importance and function of finite subjectivity in the Hegelian philosophy. In order to do so, let us focus on the interpretation of parts of the book Phenomenology of Spirit from 1807, that expose the development of subjectivity as its central theme. Our interpretation of the last figures of Reason led us to the conclusion that finite subjectivity as a single individual participates fundamentally in the production and effectiveness of the concepts, for we find that because of its nature, determined as the negative character of the spirit, it is never totally overcome and dissolved in universality.
\end{abstract}

Keywords: Subjectivity. Concept. Necessity. Effectiveness.

\title{
Resumen
}

Esta investigación procuró solucionar el problema que implica la importancia y función de la subjetividad finita en la filosofía hegeliana. Por eso, a centralidad se situa en la interpretación de partes de la obra que expone el desarrollo de la subjetividad como su tema central, la Fenomenología del Espíritu de 1807. Nuestra interpretación de las ultimas figuras de la Razón nos llevó a la conclusión de que la subjetividad finita, mientras que la individualidad singular participa de manera fundamental de la producción y de la efectivación de los conceptos, pues verificamos que debido a su naturaleza, determinada como el carácter negativo del espíritu, nunca es totalmente superada y disuelto en universalidad.

Palabras clave: Subjetividad. Concepto. Necesidad. Efectividad.

\section{Introdução}

Nossa pesquisa tem como pressuposto a interpretação de uma figura da consciência da Fenomenologia do Espírito, escrita por G. W. F. Hegel, em 1807, que é intermediária, ou seja, derivada e resultado do processo de figuras anteriores a ela, a figura da Razão. Como pressuposto para tal exposição, buscamos verificar e expor sua justificativa como uma figura válida e fundamentada pelos seus desenvolvimentos anteriores no processo fenomenológico. De uma maneira geral, a justificativa, para Hegel, para o ponto de vista da consciência racional é a necessidade do conceito, a ciência especulativa, e o lugar de sua exposição por excelência dessa ciência é Ciência da Lógica. Entretanto, vemos que há elementos presentes já na Fenomenologia 
do Espírito para conhecermos o que Hegel compreende como ciência. Em busca de uma base indispensável para nossa argumentação, examinaremos nesse artigo os passos argumentativos do que consideramos o núcleo da figura da razão, elementos fundamentais para a compreensão dos momentos seguintes da obra, a saber, o momento denominado a Razão Ativa.

\section{Razão ativa: a efetivação do conceito pela subjetividade}

Nesse novo momento do desenvolvimento racional, que se segue a uma posição observadora da consciência para comprovar a certeza de sua identidade com a realidade, Hegel nos revela uma das características que devemos levar em conta no movimento fenomenológico: suas idas e voltas às posições que de um ponto de vista já foram superados, mas são conservados em pontos de vista mais concretos, tal qual se define a Razão. O desenvolvimento da subjetividade em direção ao saber efetivo não pode ser considerado de modo algum linear:

A razão observadora repetira no elemento da categoria o movimento da consciência, isto é, a certeza sensível, a percepção e o entendimento, - assim também essa razão [ativa] percorrerá de novo o duplo movimento da consciência de si, e da independência passará à sua liberdade³.

Agora, a consciência racional deve ser definida como a relação entre indivíduos, que, para além de buscarem conhecer e descrever o mundo e comprovar a veracidade de seu saber, produzem a sua realidade e reconhecem sua universalidade não apenas em um objeto exterior, mas em outros indivíduos, reconhecidos como consciências-de-si livres, assim como na própria realidade, tomada como substância universal efetivada pela atividade dos indivíduos em conjunto. Trata-se aqui da descrição da concepção de Hegel da interação entre indivíduo e mundo, visto como

3 HEGEL, G. W. F Fenomenologia do Espírito Trad. Paulo Menezes. Petrópolis: Ed. Vozes, 2000. 
substância espiritual efetivada, ou seja, uma forma do conceito efetivada. É a transição fenomenológica entre Razão e Espírito, que, como vemos, não corresponde a um avanço linear que delinearia um degrau anterior e outro posterior, mas da interação de dois momentos do espírito, em sua diferenciação como universalidade e singularidade, positividade e negatividade.

Quando falamos aqui do conceito, nos referimos ao elemento do pensamento tal qual é tratado pela filosofia especulativa da Ciência da Lógica, mas em sua concretude efetivada em uma substância ética:

Tomemos em sua realidade essa meta alcançada: o conceito, que já surgiu para nós - isto é, a consciência-de-si reconhecida, que tem em outra consciência-de-si livre a certeza de si mesma, e aí precisamente encontra sua verdade.\{...] O que vemos patentear-se nesse conceito é o reino da eticidade. ${ }^{4}$

Aqui, a figura da consciência racional vê-se em perfeita harmonia com o mundo em que está inserida, da qual é membro e nela reconhece seus próprios anseios e expressão de sua liberdade. "É na vida de um povo que o conceito tem, de fato, a efetivação da razão consciente de si e sua realidade consumada"5.

O indivíduo está nesse momento do processo diluído na universalidade da substância ética, que o compõe e o sustenta em sua universalidade. Sua vida e cada ação sua toma significado a partir da sua imersão como membro de uma eticidade universal, que se traduz como o espírito de um povo, com suas leis e costumes.

O trabalho do indivíduo para [prover a] suas necessidades, é tanto satisfação das necessidades alheias quanto das próprias; e o indivíduo só obtém a satisfação de suas necessidades mediante o trabalho dos outros ${ }^{6}$

\footnotetext{
4 HEGEL, 2000, p. 222.

5 Ibid., p. 222.

6 Ibid., p. 223.
} 
A subjetividade, que acompanhamos seu processo de formação e de independência, percorre um momento de pura positividade, algo como uma relação indivíduo-mundo perfeita, com uma harmonia irreparável: "em um povo livre, a razão em verdade está efetivada"7 É o que Hegel conclui a partir do desenvolvimento de uma consciência verdadeiramente racional e uma individualidade ativa, livre das amarras de sua singularidade e reconhecendo a plenitude de sua universalidade. Entretanto, como veremos, a efetivação e implementação do conceito pelo indivíduo não se dá de forma tão uniforme e exata assim, pois como já foi dito, a característica mais essencial da subjetividade finita é a negatividade, e, enquanto tal mesmo que não plenificando o conceito, o põe em movimento, pois é expressão do mesmo, assim se reconhece, mas não o é em sua pureza: permanece como indivíduo, exteriorização e diferenciação do Espírito universal.

Como singularidade, não plena em uma unidade conceitual com a universalidade do espírito, a individualidade inverte o movimento anterior e ela mesma dissolve a universalidade da substância ética: nega e vai contra as leis e costumes instituídos. ${ }^{8}$

Enquanto individualidade singular, ativa, cuja essência é negatividade e movimento, não se sustenta em sua relação imutável com leis fixas. Não se satisfaz mais nela, e busca agora produzir uma eticidade de acordo com suas necessidades.

A substância ética é rebaixada a predicado carente-de-si, cujos sujeitos vivos são indivíduos que através de si mesmos têm de implementar sua universalidade, e por conta própria, cuidar de seu destino. ${ }^{9}$

Ibid., p. 223.

8 HEGEL, 2000, p. 224.

9 Ibid., p. 225. 
Essa cisão apresentada nesse ponto do desenvolvimento da racionalidade descrita no processo fenomenológico representa uma relação desigual entre indivíduo e mundo, nas quais ocorre a gênese da moralidade, a ação dos indivíduos por impulsos naturais ou interesses singulares e também a ação conforme a um fim, em vista da necessidade da individualidade de produzir um mundo de acordo com o conceito que elabora como dever e busca efetivá-lo, pois precisa produzir um mundo que reconheça como seu para comprovar sua verdade e não se perder novamente na certeza pura de uma consciência singular que não reconhece a exterioridade como sua:

Aparece a consciência cindida entre essa efetividade encontrada e o fim que implementa através do suprassumir da efetividade, e, antes, faz dele efetividade em lugar dessa. ${ }^{10}$

Segundo Hegel, essa cisão entre lei efetivada universal e lei cuja singularidade busca efetivar, chamada por ele "lei do coração", se desenvolverá em uma experiência que terá como resultado uma nova dissolução da singularidade na universalidade, pois uma tal lei meramente singular e finita não pode se manter frente a universalidade e infinitude, conceitos mais concretos dos quais a singularidade é um mero momento. Entretanto, como veremos a seguir, fica difícil manter uma concepção de individualidade que permaneça em harmonia com a substância ética efetivada como leis e costumes, dada a natureza da subjetividade singular, o movimento de posição, negação e reposição do conceito na efetividade é garantido por ela, que nada mais é que o próprio Espírito se pondo em movimento. Tal aspecto se mostra, na perspectiva da Ciência da Lógica, como o automovimento do conceito, cuja consciência é uma efetividade conceitual, que aparentemente estão diferenciadas, mas são idênticas do ponto de vista do pensamento puro.

10 lbid., p. 226. 


\subsection{A emergência da singularidade na ação racional}

No desenvolvimento da figura da individualidade ativa, vemos que no processo fenomenológico da consciência racional há uma argumentação que revela a importância de um aspecto puramente singular da consciência racional. A identidade entre consciência e objeto, apenas suposta no início como certeza da consciência, deve se efetivar como uma substância, um ser e, portanto, não ser concebida como uma identidade meramente formal, mas efetiva e concreta. Trata-se aqui de um elemento do argumento fundamental se buscamos revelar o papel essencial da individualidade singular no desenvolvimento da filosofia hegeliana, pois nos defrontamos com diversas interpretações no hegelianismo que conclui como indiscutível a dissolução da individualidade na universalidade da substância ética em que está inserida. De fato, o próprio Hegel, como veremos, direciona o desenvolvimento da razão defendendo esse fim para a singularidade. Entretanto, nossa interpretação percebe que essa intenção de Hegel não se conclui efetivamente e a singularidade permanece de um certo modo em oposição à universalidade ética. Todavia, não podemos perceber essa dualidade como uma separação inconciliável, pois permanece um jogo entre a singularidade finita e a universalidade infinita, em uma interação na qual, ambas, como sendo dois aspectos do espírito, permanecem em uma dualidade dialética, sendo que a singularidade mantém o aspecto negativo do movimento do conceito e a universalidade infinita, enquanto substância ética efetivada, mantém o seu lado positivo. Na atividade da singularidade frente à universalidade, o jogo inverte, quando o negativo da singularidade impõe a positividade por meio da efetivação do que determina sua ação, o conceito pensado como dever e substância ética converte-se no negativo, pois permanece em oposição ao conceito que a individualidade busca efetivar, em sua imobilidade dada como uma rede categorial de conceitos já efetivados como leis e costumes. A partir de tal jogo, se dá o movimento do espírito que, assim, não permanece igual a si mesmo nem segue sua configuração já determinada, pois pelo movimento do conceito que ocorre de dois modos, 
como pensamento puro e como pensamento da consciência, percebemos que o segundo modo de movimento, pela ação da consciência, efetiva novas configurações do conceito e, portanto, novos modos de substância ética, ou novos espíritos do mundo, segundo a definição de Hegel dada no prefácio à Fenomenologia do Espírito como individualidades históricas, e suas particularidades diferenciadas, os espíritos dos povos.

Desse modo, o pensamento do conceito pela consciência não é o pensamento puro do conceito por si mesmo, e a consciência está de certa forma subordinada a ela, como vemos no desenvolvimento fenomenológico da formação da identidade entre pensamento e ser. Mas justamente essa diferença, na qual o conceito perde sua pureza como categoria lógica e entra no elemento da efetividade por meio do pensamento e da ação da consciência, vemos um movimento em que o conceito diferencia-se de sua forma pura e, ao penetrar no âmbito da singularidade finita, com todas suas limitações, contradições e interesses particulares, penetra também em um âmbito que está imerso na forma da contingência da ação e do resultado da ação da individualidade. Os interesses particulares do indivíduo passam a fazer parte do jogo e sua ação passa a ter efeitos imprevisíveis a partir do ponto de vista do pensamento puro do conceito. Para compreender esse jogo, vejamos como Hegel desenvolve a participação da particularidade dos interesses do indivíduo na efetivação de si mesmo como consciência racional e, com isso, como trabalha com a necessidade de resolver o problema da dualidade gerada entre a singularidade do indivíduo e a universalidade da substância ética. Nesse caminho, verificarmos a solidez de sua solução e se podemos visualizar possíveis problemas nessa solução e procurar outros modos de resolver o problema.

A necessidade de uma ação por parte da consciência racional de agir, de reconhecer a objetividade como a si mesma passa por um retorno ao movimento que ocorreu na figura da autoconsciência, quando da relação de dependência e independência da consciência-de-si. Após revelar a oposição frente aos costumes efetivados na substância ética, e, coincidentemente, frente às outras consciências, elementos como o desejo e a busca por sua satisfação 
entram novamente no desenvolvimento fenomenológico, agora com a finalidade de concretizar a certeza da razão de sua identidade com a realidade.

Tal momento do desenvolvimento da razão é essencial para fundamentarmos nosso argumento sobre a função da singularidade no movimento do conceito porque é a primeira vez no desenvolvimento fenomenológico que reconhece a necessidade como conceito determinante de sua própria essência e, posteriormente, da própria substância ética".

No início, como referimos anteriormente, ao afirmar sua singularidade como elemento efetivo da produção da sua identidade com a objetividade, $\mathrm{e}$ para isso afirmar sua oposição às determinações da substância ética, repete o ciclo de sua emergência como consciência de si, vendo a objetividade como objeto a ser desejado e fruído. Entretanto, ao buscar a efetividade da sua singularidade na satisfação do seu desejo, agora enquanto consciência racional sabe que o objeto que o satisfaz é uma expressão dele mesmo, enquanto representação. Mas, ao mesmo tempo reconhece-se como independente, repetindo no patamar da razão a relação entre autonomia e dependência expressa no capítulo da Consciência-de-Si. No entanto, o outro não se mostra apenas como outro objeto ou consciência-de-si, mas, como consciência racional, percebe toda a exterioridade como categoria, ou seja, uma universalidade efetivada. Percebendo a dependência de sua satisfação em relação a uma universalidade, a sua própria essência independente como singularidade se desfaz, sendo, experienciando, nesse momento sua dissolução frente a uma universalidade, que determina o que o satisfaz.

Retornando, agora em um outro patamar, sua oposição em relação á universalidade em que está inserida, a individualidade singular reconhece que está sujeita a uma necessidade que a determina, que se impõe sobre ela, e a anula. O seu agir, que tem o fim de obter um prazer, resultado da fruição do objeto, como é determinado por uma mediação com um objeto, ainda que se reconheça nele como o produzindo em uma representação, ao

"Cf. HEGEL, 2000 p. 228 
reconhecer a universalidade dessa representação o eleva para um além de si mesma, um outro para ela, elementos como categorias que tanto em sua relação com a vida natural quanto em sua relação com a cultura determinada como substância ética, definem qual será sua ação, o que lhe dá prazer, e assim sua singularidade se mostra como determinada por uma universalidade.

É o que se chama necessidade; com efeito, necessidade, destino, são justamente uma coisa que ninguém sabe dizer o que faz, quais suas leis determinadas e seu conteúdo positivo. Porque é o conceito absoluto intuído como ser, a relação simples e vazia, mas irresistível e imperturbável, cuja obra é o nada da singularidade. ${ }^{12}$

Isso significa que, nesse momento do desenvolvimento fenomenológico se revela a necessidade com a qual se deparará a individualidade em seu agir, e que Hegel sustentará que, a despeito dos movimentos anteriores e posteriores à razão como individualidade ativa, determinará a ação e o destino da singularidade que está inserida em uma substância ética e, portanto, em uma rede conceitual efetivada.

Para que possamos verificar se há um espaço para a contingência na ação subjetiva, por meio do exame de como Hegel sustenta sua participação na implementação do movimento do conceito, ao mesmo tempo que a coloca como subjacente ao conceito de necessidade, devemos esclarecer como essa categoria aparece na Fenomenologia do Espírito, e como se dá sua relação com a singularidade do indivíduo concreto:

A necessidade é essa conexão firme, porque as coisas conectadas são essencialidades puras, ou, abstrações vazias: unidade, diferença e relação são categorias; cada uma delas nada é em si e para si, mas só em relação ao seu contrário;

12 HEGEL, 2000, p. 229. 
portanto não podem separar-se uma da outra. É através de seu conceito que mutuamente se referem, pois as categorias são os conceitos puros mesmos: esta relação absoluta e esse movimento abstrato constituem a necessidade. A individualidade somente singular, que só tem, de início, o puro conceito de razão por seu conteúdo, em vez de precipitar-se da teoria morta para a vida, o que fez foi jogar-se na consciência de sua própria carência-de-vida, e só participa de si como necessidade vazia e alheia-como efetividade morta. ${ }^{13}$

Vemos como a categoria da necessidade articula os momentos que estruturam toda a experiência da consciência, em seu processo de oposição e identificação com a objetividade. Segundo Hegel, não articula apenas a experiência da consciência, mas como relação absoluta dos conceitos que isolados, não tem significação, mas também a própria rede categorial determinada como pensamento puro e expresso na Ciência da Lógica como ciência especulativa. Entretanto, nesse momento da experiência da consciência apresenta-se como seu oposto, como uma efetividade sem vida, ou seja, dada, estanque e imutável, e por isso morta: "a absoluta dureza da singularidade se espatifa em contato com a efetividade, igualmente dura e contínua"14. É uma positividade fixa na qual a individualidade como expressão da singularidade do Espírito e, portanto, como negatividade pura, não a reconhece como si, revelando uma oposição que, se Hegel quer sustentar sua posição de identidade produzida entre sujeito e objeto e da unidade do saber absoluto, deve resolver.

Mas, ao mesmo tempo, se Hegel quer manter as suas posições definindo o absoluto como processo, o espírito como movimento de diferenciação e reconciliação consigo mesmo, e o automovimento do conceito como estrutura tanto do pensamento como da realidade, deve reconhecer um espaço para a contingência na ação da subjetividade, que como vimos, é uma expressão do

\footnotetext{
13 HEGEL, 2000, p. 230

14 Ibid., p 230
} 
conceito, não se diferenciando dele, sendo apenas sua efetividade concreta. A solução, para Hegel, é reconhecer a necessidade não como oposta, mas como expressão do $\mathrm{Si}$, da unidade do Espírito em seu aspecto subjetivo e objetivo, ou seja, a necessidade não é um oposto, mas sua própria essência. Mas como veremos, podemos perceber problemas nessa passagem da necessidade como outro para necessidade como si: "[...] a consciência tornou-se, antes, um enigma para si mesma: as consequências de seus atos não são, para ela, atos seus"15.

\subsection{O reconhecimento da necessidade no movimento da consciência racional}

Para Hegel, há uma oposição entre a efetividade da ação do indivíduo que se reconhece como consciência racional, ou seja, em uma relação de identidade com a objetividade, que foi realizada pelo sua oposição e produção da exterioridade, e seu limite ao deparar-se com a necessidade dura que rege a objetividade. A solução para essa oposição é o reconhecimento de que essa necessidade não lhe é apenas exterior, mas também interior, ou seja, o constitui em sua própria essência singular.

Não é imediato que um elemento estranho à sua ação como uma determinação necessária da realidade possa ser mediado e interiorizado pela individualidade. A mediação sem uma boa justificativa conduz, como Hegel aponta, a uma dissolução da própria individualidade e de sua propriedade de produzir a própria realidade por si, eliminando a liberdade de seu agir. No entanto, a mediação fornecida pelo agir em busca do gozo pelo prazer conduz de fato ao reconhecimento de um aspecto determinado desse desejo, em conjunto com o reconhecimento de outras consciências-de-si que agem da mesma forma, tal agir toma a forma de uma universalidade, e o que parecia uma ação singular se mostra como uma ação orientada universalmente, ou seja, permeada pela necessidade.

15 HEGEL, 2000, p. 230. 
Desse modo, esse agir da consciência conforme uma necessidade não significa que ela seja determinada por algo exterior à individualidade singular, no qual ela nada interfira. A necessidade apontada anteriormente tende a se referir ao que a consciência racional conserva da consciência natural, seu elemento vital, mas enquanto consciência cultivada dentro de uma substância ética, mesmo que aceitando ou se opondo aos costumes, verificamos que a necessidade se manifesta no agir como uma lei, um dever que determina a ação do indivíduo e sua ação conforme esse dever determina sua intervenção no mundo e a produção do mesmo. Isso significa que o conceito de necessidade se efetiva na sua unidade com a singularidade do espírito, ou o $\mathrm{Si}$, que é a consciência racional concretizada em uma individualidade singular e ativa, como uma necessidade singular, uma lei singular. É o que Hegel chama "a lei do coração", pois possui um caráter essencialmente subjetivo, de um lado, mas universal, de outro, enquanto lei ou dever que determina um fim para a ação, que deve ser efetivado.

Esse momento, que revela a argumentação hegeliana em busca de um elemento para mediar a singularidade da ação com a universalidade de uma lei, é fundamental em nosso argumento para revelar o papel da subjetividade no movimento do conceito, pois como veremos, embora Hegel procure resolver o caráter singular e contingente da individualidade dissolvendo-o, de certa forma, com o conceituar puro, pois se mantido conduz a uma oposição inconciliável ao seu movimento especulativo, pois este deve ter a determinação da necessidade absoluta, a eliminação da contingência significa também a eliminação da singularidade e, portanto, do próprio aspecto negativo do Espírito, que permite sua concepção como processo e desenvolvimento. Procurar um lugar para a contingência não significa retornar a uma visão próxima a do ceticismo, na qual qualquer coisa pode ser qualquer coisa, conduzindo a uma concepção filosófica em que o acaso é elemento central e o relativismo sua característica principal. Tendo como ponto de partida fundamental o automovimento necessário do conceito, quando ele se determina como subjetividade e consciência e elabora leis para sua ação e busca efetivá-las, esse ato, ou seja, a rea- 
lização ou concretização de um conceito, pode apresentar-se como um espaço de indefinição sobre como se dará a passagem desse conceito do pensamento para a efetividade, pois a individualidade, além de produzir, precisa também se reconhecer nela:"[...] Resta saber se sua efetivação corresponde a tal conceito (o fim da lei determinada pela necessidade), e se nela a consciência-de-si experimentará essa lei como sua essência".16

Essa lacuna entre conceito e sua efetividade parece se revelar no desenvolvimento da consciência racional enquanto individualidade ativa e individualidade que atingiu a unidade em-si e para-si mesma, como veremos a seguir.

Dentro de uma substância ética efetivada, ou, dizendo de outro modo, de um sistema de leis concreto, se revela a objetividade, a universalidade efetivada como uma configuração do espírito, determinada por um movimento próprio que a produziu, permeada pela necessidade do movimento do conceito e da ação de cada indivíduo que participou desse processo. Entretanto, há a lei da consciência racional, aqui determinada como indivíduo singular que age e que passou pelo movimento que expomos até aqui, o qual manifestou a necessidade e a universalidade presente no seu agir, que é chamada por Hegel de lei do coração:

\footnotetext{
[...] (Temos) a contradição entre a lei e a singularidade: De um lado, pois, essa efetividade é uma lei, pela qual a individualidade singular é oprimida: uma violenta ordem do mundo, que contradiz a lei do coração. De outro lado, é uma humanidade padecente sob essa ordem, que não segue a lei do coração, mas está submetida a uma necessidade estranha. ${ }^{17}$
}

A lei do mundo se mostra estranha e opressora para essa individualidade, pois é oposta à singularidade de sua própria lei. $\mathrm{A}$ individualidade opera agora não com a finalidade de satisfazer seus próprios prazeres particu-

\footnotetext{
16 HEGEL, 2000, p. 231. O texto entre parênteses é do autor.

17 HEGEL, 2000, p. 231
} 
lares, mas em vista da necessidade e universalidade que descobriu em seu agir, busca uma satisfação universal, um bem universal. Diante da ordem instituída que não é de acordo com o que, segundo a sua lei, deveria ser, considerando-a fonte de sofrimento dor para os que a devem obedecer e distante do bem que deveria proporcionar, pode contentar-se em viver conforme a lei efetivada em uma determinada ordem social, ou pode querer impor a sua lei à essa ordem do mundo que não considera adequada.

Essa parte da argumentação de Hegel permite pensar diferentes formas de situações políticas e alterações sociais que ocorreram na história, e, como veremos mais adiante, Hegel considera ultrapassada, tanto fenomenologicamente quanto historicamente, tal posição de uma singularidade querendo impor uma mudança conforme sua vontade a uma ordem social e legal instituída, como veremos em sua crítica à essa pretensão de uma individualidade singular, parecendo tender a uma posição mais conservadora. Entretanto, estamos reconstruindo os passos de sua argumentação justamente para procurar revelar outro aspecto do desenvolvimento fenomenológico a partir desse argumento, no qual o valor da ação singular deve ser mantida elemento de mudança e transformação do Espírito e, portanto, de caráter histórico. Consideremos os passos que se seguirão a esse movimento.

Para Hegel, quando uma individualidade singular consegue efetivar a sua lei no mundo, a partir do cumprimento do que considera seu dever, essa lei que era subjetiva torna-se objetiva e, enquanto objetividade efetivada, torna-se a nova ordem e portanto, exterior à própria individualidade singular, assim como era a primeira ordem que ela não considerava adequada. Esse novo caráter da lei do coração, agora efetivada, toma contornos para Hegel que o indivíduo que a promoveu não se reconhece nela de modo algum, justamente devido ao caráter exterior que agora possui ${ }^{18}$. Além disso,

\footnotetext{
18 Contra essa ideia, podemos perguntar: será mesmo que de nenhum modo uma individualidade pode reconhecer sua ação quando efetivada, apenas por ser exterior? Mas gostaríamos de adentrar nessa questão em outro momento, pois aqui nos determinamos a seguir a argumentação hegeliana e interpretar seus resultados, que aparecem no final do capítulo da Razão, em sua transição para o capítulo Espírito.
} 
enfrenta a vontade e a lei singular de outras individualidades, que também buscam efetivar aquilo que consideram necessário segundo suas próprias leis, o que transforma a ordem social em uma espécie de guerra permanente entre as individualidades. Podemos interpretar essa lei do coração que cada indivíduo possui em seu agir como diferentes redes conceituais que poderiam organizar uma sociedade, visando o bem comum, mas de maneiras diferentes. No entanto, parece que Hegel nega a possibilidade de uma lei despótica efetivada ou de uma ordem injusta, pois argumenta que a introdução de uma lei de origem singular na ordem universal é uma espécie de "perversão" da mesma, e nesse movimento de efetivação de uma lei singular necessariamente essa lei vai se reconhecer como já efetivada, devido à sua forma de universalidade que compartilha com a ordem que está já efetivada. O agir do indivíduo possui um conteúdo singular, mas uma forma universal, pois está definido pela necessidade do dever e do fim que o mesmo lhe impõe, o que de toda forma é um conceito pensado pela individualidade e que por sua natureza especulativa busca efetivar-se.

Desse modo, segundo Hegel, o que parece ser uma ação individual é na verdade uma ação da própria universalidade atuando sobre si mesma, que coloca o indivíduo como portador de conceitos que possuem seu próprio movimento, e permite que a substância ética não seja algo fixo e morto, mas dotado de um movimento interno e, portanto, vivo. A ordem instituída da qual a individualidade faz parte, e em sua experiência percebe como exterior, nesse processo vemos que é expressão da própria ação dos indivíduos que buscam efetivar seus interesses particulares, considerando-os universais. Até aí se sustenta a tese de que a singularidade se dilui na universalidade de maneira unilateral, o que percebemos também nos movimentos posteriores descritos no desenvolvimento da subjetividade finita na Fenomenologia do Espírito. No entanto, como veremos, o ideal de Hegel de uma subjetividade que se identifique plenamente na universalidade não se sustenta por muito tempo se seguimos seu próprio desenvolvimento fenomenológico.

A individualidade que efetivou sua lei e não se reconhece nela gera uma duplicidade, chamada por Hegel de um "desvario da consciência", pois 
transita em sua ação a considerar, indo de um lado a outro, o universal como singular e o singular como universal, o essencial como o inessencial, não conseguindo determinar o conceito do que the aparece, pois busca manter sua singularidade intocada como sua própria essência, preservando assim seu caráter individual e oposto à universalidade que está inserido. Essa luta pela preservação de sua individualidade gera a presunção de colocar-se como mais verdadeiro, efetivo e concreto que a própria universalidade que está efetivada, apontando a própria universalidade como pervertida, pois não segue a lei da singularidade como pensa que deveria. Todavia, para Hegel, segue aqui o desvario pois a individualidade não reconhece a ordem instituída como expressão de sua ação nem como a sua própria condição de existência, pois nela se formou e está inserido. Novamente vemos aqui Hegel considerar de forma universal a ordem instituída como certa e justa, que deve ser considerada como essencial e necessária.

A unidade entre a lei instituída, objetivada, e os indivíduos, com suas próprias leis subjetivas, se dá da seguinte forma: ainda que em suas disputas sobre qual lei singular deve ser efetivada, os indivíduos não se reconheçam na lei que vigora, percebem que fora dela não são nada, pois ela lhe dá uma essencialidade e permite as suas próprias condições de indivíduos. Já a ordem instituída não pode ser reconhecida sem os indivíduos que colocam em prática suas determinações, a movimentam e efetivam, pois sem eles seria algo abstrato e morto.

Entretanto, vemos estabelecida uma relação de dependência mútua, mas não uma identidade. A oposição permanece, e Hegel passa a chamar a ordem instituída de "curso do mundo", no qual as oposições e disputas entre os indivíduos e a ordem estabelecida permanecem, além das próprias oposições entre os indivíduos. Sem a efetivação de uma identidade verdadeira, os indivíduos enquanto subjetividades singulares continuam tendo seu papel de pensar e efetivar os conceitos na realidade, sendo assim o que a coloca em movimento e permite pensá-la como processo. Embora a linha do argumento de Hegel pareça, como vimos, tender a um enfraquecimento da importância da subjetividade, pois de todo modo ela 
está sempre condicionada por uma universalidade, sua propriedade de expressão da negatividade pura, tanto quando de sua experiência com objetos como de quando pensa conceitos e os efetiva segundo seu agir a mantém no círculo dialético de posição e reposição da realidade, a despeito de uma nova figura que tem como fim justamente ultrapassar o alcance da ação da individualidade puramente singular: a consciência virtuosa.

Nesse novo momento revelado no desenvolvimento da consciência racional, a dicotomia entre lei e indivíduo deve ser superada pela superação do indivíduo enquanto singularidade, considerando a ordem instituída, agora chamada de curso do mundo, como essencial, universal e necessária. A formação de uma individualidade real deve ultrapassar seu caráter singular para que possa ser efetivamente universal e concretizar a identidade entre subjetividade e objetividade, objetivo de toda argumentação do capítulo sobre a Razão.

A individualidade singular, que promoveu os movimentos e dualidades anteriores, deve ser, segundo Hegel, "disciplinada” segundo a universalidade. A virtude se revela a partir dos movimentos anteriores como a "verdadeira" lei do coração, pois, sendo o sacrifício de todo desejo ou objetivo particular, é a "lei de todos os corações": é universal, e se configura como o Bem. A partir dessa ideia suprema que deve efetivar-se, a virtude se sobrepõe à individualidade e a coloca como verdadeiro agir, e a consciência virtuosa, ao reconhecer que o curso do mundo foi produzido pela interação das ações dos indivíduos, considera que deve ultrapassá-lo também, pois não admite nenhum resquício de particularidade ou de contingência em seu ideal de bem.

Com esse objetivo, a consciência virtuosa seria, assim como a individualidade que age segundo a lei do coração, uma consciência racional que luta contra o curso do mundo, buscando efetivar seus ideais na forma de conceito. Mas, ao contrário da lei do coração, não quer afirmar sua individualidade. Ao contrário, quer eliminá-la e implementar no curso do mundo um conceito completamente universal, com o bem. Entretanto, como vemos no texto, o curso do mundo, como universalidade já concreta, é considerado por Hegel inabalável, cuja própria virtude é expressão de seu movimento: 
O curso-do-mundo deveria ser a perversão do bem, por ter a individualidade por seu princípio. Só que essa individualidade é o princípio da efetividade; pois é justamente a consciência por meio do qual o em-si-essente é também para um outro. O curso-do-mundo perverte o imutável; de fato, porém, o inverte do nada da abstração ao ser da realidade. ${ }^{19}$

Vemos, em sua argumentação, como Hegel, apesar de expor um movimento que parece conduzir à dissolução da individualidade, o reconhece como essencial para o movimento da realidade posta, sendo o próprio núcleo das mudanças que se dão ao longo do curso-do-mundo. Mas essa individualidade que produz e constitui o curso-do-mundo perde seu caráter singular ao reconhecer-se nele, e passamos a conhecer a individualidade real, em seu aspecto tanto singular quanto universal, ou seja, para-si e também em-si mesma:

$O$ agir e o atarefar-se da individualidade são, pois, fim em si mesmo. O uso de forças, o jogo de sua exteriorização, são o que lhes confere vida, senão seriam o Em-si morto. O Em-si não é um universal irrealizado, inexistente e abstrato; mas ele mesmo é imediatamente essa presença e efetividade do processo da individualidade. ${ }^{20}$

\section{A produção da identidade na individualidade e suas consequências}

Com isso, seguindo nossa proposta de acompanhar a argumentação hegeliana sobre o desenvolvimento da consciência na Fenomenologia do Espírito, focando no movimento da subjetividade singular que atingiu o ponto de vista racional, atingimos um dos elementos que buscávamos: os

\footnotetext{
19 HEGEL, p. 242.

20 Ibid., 2000, p. 244.
} 
argumentos do próprio Hegel que afirmam a importância da subjetividade singular na formação e implementação dos conceitos, que, como aspecto da negatividade e exterioridade do espírito, constitui o elemento central para sua compreensão como processo e movimento, e não como algo parado e determinado em seu desenvolvimento.

Entretanto, por mais que a individualidade seja assim vista, na última seção do capítulo da Razão, a individualidade real em-si e para-si, resultado do desenvolvimento anterior da individualidade observadora e ativa, conduz a uma identificação da individualidade com a universalidade, sugerindo que, mesmo que reconhecida sua importância, Hegel mantém a ideia de que ela em um momento deve se diluir na universalidade, reconhecendo-a em si mesmo e a si mesmo na universalidade concreta, ou seja, na ordem instituída como curso do mundo, ou aspecto em-si do Espírito. Isso nos conduziria a uma forte determinação da singularidade por parte da universalidade, cuja necessidade intrínseca determinaria de forma completa o agir da individualidade. Já asseguramos sua posição acerca do lugar da individualidade, mas de que vale esse lugar se ele é inessencial, ou seja, possui sua determinação própria fora de si mesma?

Ao justificar e desenvolver o modo como se dá essa individualidade que se reconheceu como universalidade, Hegel busca exemplos e explicações sobre como se efetiva essa identidade, que, afinal de contas, é o objetivo do capítulo da Razão: justificar essa identidade, que era uma certeza e deve se tornar efetiva. Com esse objetivo, naturalmente Hegel não poderia manter uma noção de individualidade singular, pois geraria uma perene diferenciação do universal que impossibilitaria a identidade efetiva entre pensamento e realidade.

No entanto, Hegel parece esbarrar por problemas ao definir de fato essa identidade. Essa conclusão da identidade reduz a consciência racional a uma mera observadora das leis, pois percebe um problema na efetivação da identidade requerida, que apareceu anteriormente nas figuras anteriores da razão, mas não foi completamente resolvido: o conceito pensado e implementado é por diversas vezes completamente do conceito efetivado. Suas afirmações, como por exemplo: 
Uma diferença na substância ética simples é, para ela, uma contingência, que vimos no mandamento determinado produzir-se como contingência do saber, da efetividade e do agir ${ }^{21}$

As oposições ainda permanecem, gerando um movimento contingente no processo da substância ética. Mesmo buscando uma universalidade efetiva, parece que não consegue avançar de uma universalidade ainda formal:

No nosso examinar (das leis), a compacta substância universal estava frente à determinidade que se desenvolvia como contingência da consciência na qual a substância entrava. Aqui desvaneceu um dos membros da comparação: o universal já não é a substância essente e válida [...] mas é o simples saber ou forma que compara um conteúdo somente consigo e o observa, [a ver] se é uma tautologia. ${ }^{22}$

Vemos que Hegel reconhece que a universalidade buscada não se sustenta, pois é ela mesma não efetiva, se a retiramos de sua interação com a individualidade singular. Embora a contingência da ação singular deva aparentemente ser eliminada para os propósitos de Hegel, sem ela a própria efetividade da universalidade e a justificação da identidade entre sujeito e objeto ficam comprometidos, retornando ao seu aspecto abstrato que Hegel por vezes ultrapassou na razão ao reconhecer a participação da individualidade na constituição do universal, mesmo com todas suas limitações. Vimos que de certo modo, a individualidade é também expressão da universalidade, enquanto conceito que sabe de si, mas também é diferenciação dela pelo seu aspecto inerentemente negativo e singular, o que dota, por conseguinte, seu movimento com uma forma contingente, em um jogo de conhecimento, efetivação, reconhecimento ou negação dos conceitos que busca implementar, ao colocar-se como negatividade da substância ética.

\footnotetext{
21 HEGEL, 2000, p. 264.

22 Ibid., loc. cit.
} 
As leis não são mais dadas, mas sim examinadas. E as leis já foram dadas à consciência examinadora, que acolhe seu conteúdo simplesmente como é, sem adentrar-se na consideração da singularidade e da contingência que aderiam à sua efetividade, como aliás fazemos nós. A consciência examinadora fica no mandamento como mandamento, e procede com respeito a ele de modo igualmente simples, como é simples seu padrão de medida. ${ }^{23}$

Percebemos essa limitação no argumento hegeliano para defender a efetividade de uma universalidade que permanece formal, pois busca a solução para a manutenção dessa universalidade apelando a aspectos meramente formais, a tautologia e a não contradição do próprio conceito, abandonando, além de sua concepção de consciência como negatividade pura e devendo ser agora positividade pura, o próprio caráter especulativo do conceito.

E mais, procurando defender seu ponto de vista, afirma:

[...] não tem cabimento nem leis determinadas, nem um saber dessas leis. Só a substância é a consciência de si mesma como essencialidade absoluta, a qual, portanto, não pode abdicar nem da diferença nela [presente], nem do saber a seu respeito. Se o legislar e o examinar demonstraram não serem nada, isto significa que ambos, tomados isoladamente, são momentos precários da consciência ética. O movimento, em que surgem, tem o sentido formal de que a substância ética, através desse movimento, se apresenta como consciência. ${ }^{24}$

Como considera que elementos como a contingência, a singularidade e a diferença são momentos precários do conhecimento e do próprio desenvolvimento do conceito e do Espírito ${ }^{25}$, e percebendo que há sempre um

\footnotetext{
23 HEGEL, 2000, p. 266.

24 lbid., §432, p. 266.

25 O chamado "viés para o uno". Cf. LUFT, 2001.
} 
resíduo de singularidade no movimento do universal, Hegel busca superar esse problema igualando formalmente universalidade e singularidade, tomando a própria substância ética como consciência. No entanto, essa identidade forçada permanece formal, como um ideal, não se sustentando efetivamente, pois o negativo presente na essência da consciência a repele de uma identificação com a universalidade pela sua própria natureza singular, como dois ímãs de polo idêntico se comportam ao tentarmos aproximá-los. De fato, podemos pensar que na ciência especulativa, como movimento do pensamento puro, não há consciência, mas também não há substância ética efetivada, pois precisa justamente da ação da individualidade para produzir-se e não permanecer como um conceito abstrato.

Vejamos como Hegel acaba o capítulo buscando justificar sua posição:

As leis são. Se indago seu nascimento, e as limito ao ponto de origem, já passei além delas: pois então eu sou o universal, e elas, o condicionado e o limitado. Se devem legitimar-se a meus olhos, já pus em movimento seu ser-em-si, inabalável, e as considero como algo que para mim talvez seja verdadeiro, talvez não seja. Ora, a disposição ética consiste precisamente em ater-se firmemente ao que é justo, e em abster-se de tudo o que possa mover, abalar e desviar o justo. [...] Portanto, não é porque encontro algo não-contraditório que isso é justo; mas é justo porque é o justo. Algo é propriedade de alguém. Isso é o fundamento. Não tenho que raciocinar a propósito, nem perquirir ou descobrir toda sorte de pensamentos e correlações, considerandos; nem cogitar em estatuir leis ou examiná-las. Por tais movimentos de meus pensamentos, eu subverteria aquela relação já que de fato poderia a meu bel-prazer fazer que seu contrário fosse conforme meu saber tautológico e indeterminado e erigi-lo em lei. ${ }^{26}$

${ }^{26}$ HEGEL, §437, p. 268-269. 
Vemos que Hegel, nesse momento com o objetivo de se elevar das limitações da singularidade e erigir uma universalidade plena e efetiva, penetrando nas figuras do Espírito mesmo, nega totalmente a possibilidade de conhecimento e ação para a consciência como singularidade finita. Entretanto, a identidade necessária e buscada para tal fim não foi atingida, pois o próprio conceito de identidade foi deturpado quando se nega a própria possibilidade do saber singular, que, em seu conceito especulativo, o universal deve conservar o singular, e não suprimi-lo. Dizer que o justo é justo porque é justo não justifica nem determina a validade do conceito de justiça que está efetivado ou em vigor. Entendemos que esses argumentos de Hegel são apontados para justificar a identidade e eliminar os problemas causados por uma singularidade atuante.

Nos momentos que antecedem o capítulo da Razão, Hegel ainda revela elementos que apontam para a importância da subjetividade finita no movimento do conceito, e nesse ponto se insere nossa discussão acerca da validade de sua conclusão quando determina o modo pelo qual se efetiva a identidade entre singularidade e universalidade. Entendemos que o movimento da consciência racional, em sua busca por provar sua identidade e produzir a si e a uma ordem efetiva que seja reconhecida universalmente seja perene, um processo especulativo que une e coloca em movimento o saber como oposição ao objeto, como consciência, desejo, negação do outro, seu reconhecimento e consequente autonomia na liberdade do pensar, momentos da consciência-de-si, e observação do mundo, afirmação ou negação de uma ordem instituída e a posição de uma nova ordem, por parte da consciência racional. O desenvolvimento exposto por Hegel na Razão ativa não se encerra pela imposição da virtude e do curso-do-mundo, pois a natureza negativa da consciência pode de diversas formas reconhecer ou não a validade da ordem instituída, que se apresenta como uma rede conceitual efetivada que a ação das individualidades mantém em movimento, constituindo o caráter processual do espírito em seu conhecimento e produção de si mesmo, que será retomado como o espírito para-si no capítulo Saber Absoluto, que deverá mostrar a natureza desse saber e constituir a 
justificação fenomenológica da ciência especulativa ${ }^{27}$. Essa compreensão do desenvolvimento da razão como processo que mantém o estatuto lógico e epistemológico da subjetividade finita irá se refletir na compreensão do próprio Saber Absoluto, pois lá Hegel busca efetivar a justificação da ciência especulativa como interação do movimento em-si e para-si do espírito.

\section{Referências}

Obras originais de Hegel:

HEGEL, G. W. F. Werke in 20 Bänden. Frankfurt am Main: Suhrkamp Verlag, 1970.

HEGEL, G. W. F. Phänomenologie des Geistes. Frankfurt am Main: Suhrkamp, 1986.

\section{Traduções utilizadas}

COLLINS, Ardis B. Hegel's phenomenology: The dialectical justification of philosophy's first principles. Quebec: McGill-Queen's University Press, 2013. https://doi.org/10.3138/utq.85.3.502

KERVÉGAN, J. F. La Phénoménologie de l'esprit est-elle la fondation ultime du système de la science hégélien. [S. I.]: [s. n.], 2014.

HIPPOLYTE, Jean. Gènese et structure de la phenomenologie de l'esprit de Hegel. Paris: Aubier, 1946.

HEGEL, G. W. F. Fenomenologia do Espírito. Trad. Paulo Menezes. Petrópolis: Ed. Vozes, 2000.

HEGEL, G. W. F. Fenomenologia do Espírito. II. Tradução Paulo Meneses. 2. ed. Petrópolis: Vozes, 1993.

${ }^{27}$ Dado que, como vimos, a justificação lógica do saber especulativo se dá na própria Ciência da Lógica. 
O DESENVOLVIMENTO RACIONAL DA SUBJETIVIDADE | RAFAEL RAMOS CIOQUETTA

\section{Endereço postal}

Rafael Ramos Cioquetta

Rua Bento Gonçalves, n. 754

Bloco 37 Ap. 373

CEP 93265-350

Esteio-RS-Brasil 